\title{
EVALUATION OF EFFECT BY DIFFERENT SURFACE TREATMENT AGENTS ON RETENTION OF CUSTOM MADE CAST METAL POST AND PREFABRICATED GLASS FIBRE POST-A COMPARATIVE STUDY
}

Sunny Panthi ${ }^{1}$, Kusum Dutta ${ }^{2}$, Harpreet ${ }^{3}$, Gaurav Singla ${ }^{4}$

${ }^{1}$ Sr. Lecturer, Department of Prosthodontics and Crown \& Bridge, Bhojia Dental College and Hospital, Himachal Pradesh, India

${ }^{2}$ Professor \& Head, Department of Prosthodontics and Crown \& Bridge Pb. Govt. Dental College and Hospital, Punjab, India

${ }^{3}$ Sr. Lecturer, Department of Prosthodontics and Crown \& Bridge Pb. Govt. Dental College and Hospital, Punjab, India

${ }^{4}$ Reader, Department of Prosthodontics and Crown \& Bridge Pb. Govt. Dental College and Hospital, Punjab, India

\begin{abstract}
\begin{tabular}{r|r} 
ABSTRACT \\
ABTR
\end{tabular}
Posts are widely used for restoring endodontically treated teeth with insufficient coronal tooth structure. Custom made cast metal post and core systems have a long history of successful use due to their superior physical properties. Prefabricated post systems have recently become more popular because they can provide satisfactory results, while saving time and reducing costs. Materials and Method: Post spaces were prepared in 60 extracted caries free teeth, and divided into two main groups of 30 teeth each for cast metal and glass fibre posts. These groups were further divided into 3 subgroups of 10 specimens each I) Control group without any surface treatment, II) Specimens treated with 57\% ethanol, III) Specimens air abraded with 50um air borne alumina particles. Teeth were mounted in acrylic blocks prepared from a specially fabricated metal device. Posts were luted in the prepared post spaces with glass ionomer luting cement. Retentive strength was tested by Universal testing machine at $2 \mathrm{~mm} / \mathrm{min}$ crosshead speed. Results: Sand blasting of cast metal posts showed more significant improvement in retention compared to both control group and ethyl alcohol treated groups. In case of glass fibre posts, sand blasting significantly improved its retention compared to control group but no significant difference was observed between control and ethyl alcohol treated groups. There was also no significant difference between ethyl alcohol treated and sand blasted group. Conclusion: It was concluded that, sand blasting is an effective method to improve retention of both cast metal and glass fibre posts.
\end{abstract}

Keywords: Cast Metal Posts, Glass Fibre Posts, Alumina Particles, Surface Treatment.

Endodontically treated teeth with extensive loss of coronal tooth structure are commonly restored with a post and core and a crown. Factors indicating this type of restoration include extensive dental caries, fracture, trauma, iatrogenic loss of tooth structure and pulpal pathology, as well as the endodontic treatment itself. In addition, the loss of water content in dentin after endodontic therapy can reduce tooth resilience and, consequently, increase the probability of fracture. After endodontic treatment, the restoration of pulp less teeth is important

Corresponding Author:

Sunny Panthi

E-mail:

sunnypanthi@yahoo.co.in sunnypanthi5@gmail.com Received: $2^{\text {nd }}$ December, 2014

Accepted: $10^{\text {th }}$ March, 2015 Online: $10^{\text {th }}$ May, 2015 to ensure successful treatment outcomes.

Restorations provide protection and reinforcement of the tooth, and also prevent the passage of microorganisms and organic liquids into root canals.
Of the various post and core designs available, the most widely used can be classified into 2 basic types: metal posts and cores that are custom cast as a single piece, and 2-element designs comprising a commercial prefabricated post to which a silver amalgam or composite core is subsequently adapted. ${ }^{2}$ Cast dowel lies intimately in the root canal where it follows the root canal's morphology and evenly transfers occlusal forces on the remaining part of the root and periodontal apparatus. ${ }^{3}$ When the remaining coronal tooth structure supporting an artificial crown is minimal, the post must be capable of resisting rotation. Tooth reduction for an esthetic veneer crown combined with the dentin lost during access preparation usually leave 
minimal foundation for the retention of an artificial crown; thus the cast post and core is usually the corono-radicular stabilizer of choice for singlerooted teeth and premolars. ${ }^{4}$

Tooth-colored posts have increased in popularity since they were introduced in 1997. Retrospective and prospective clinical studies have shown an overall satisfactory performance of endodontically treated teeth restored with fiber-reinforced post systems. Tooth-colored fiber-reinforced posts have esthetic advantages, including increased transmission of light through the root and the overlying gingival tissues. Moreover, fiber-reinforced posts eliminate the problems of corrosive reactions that can occur with metal alloy prefabricated posts. An important characteristic of fiber-reinforced posts is their elastic modulus, which is similar to that of dentin, resin cements, and resin core materials. ${ }^{5}$

Post and core system has many advantages, but it cannot be considered free from limitations. The most commonly encountered restoration failure in teeth with post and core build-up is loss of retention. In general, the retention of a dowel is affected by factors involving the physical properties of both the dowel and the cement as well as the bonding of the cement to both the dowel and the tooth. Specifically, with respect to the post, this includes its length, diameter, surface structure, design, and material of construction. One factor which significantly affects the retention of post is giving different surface treatments to the post material. ${ }^{6}$

It is the purpose of this in-vitro study to evaluate the effect of two different surface treatments on the retention of custom made cast metal post and prefabricated glass fibre posts placed into prepared root canals with the glass ionomer cement.

\section{MATERIALSAND METHOD}

Sixty extracted caries free and visually assessed fracture free, human maxillary anterior teeth and mandibular premolar teeth were selected. A custom made metal device (mold) was fabricated for making the acrylic blocks (Figure 1). The dimensions of metal mold were: length $16 \mathrm{~mm}$, width $16 \mathrm{~mm}$, height $55 \mathrm{~mm}$ (Internal).

A thin layer of petroleum jelly was applied to the inner walls of the mold. Thereafter, the mold was filled with a mix of self-cure acrylic resin. A total of 60 acrylic blocks were prepared for the purpose of mounting of the teeth. Each tooth was mounted in the acrylic block till C.E.J before complete hardening of the resin, after preparing notches in the root of the teeth to prevent dislodgement during testing.

These 60 blocks with mounted teeth were divided into two main groups:

Group A- comprised of 30 specimens of cast metal posts.

Group B- comprised of 30 specimens of glass fibre posts.

Teeth were then sectioned with diamond rotary cutting instrument $1 \mathrm{~mm}$ coronal to C.E.J. The pulpal tissue was removed and the canal was enlarged with endo files upto size forty. 3\% sodium hypochlorite solution was used to irrigate the canal throughout instrumentation. Specific drill (peso reamer size 2) was marked at $9 \mathrm{~mm}$ length from tip and post space of $9 \mathrm{~mm}$ in length was prepared. This $9 \mathrm{~mm}$ post space length was taken as standard length for all specimens.

- Prefabricated glass fibre posts came in $19 \mathrm{~mm}$ length, so wax patterns $19 \mathrm{~mm}$ long $(9 \mathrm{~mm}$ inside root canal and $10 \mathrm{~mm}$ outside root canal) of 30 specimens of Group A were made. Subsequently, they were invested and casted with $\mathrm{Ni}-\mathrm{Cr}$ alloy.

- Thirty pre-fabricated $19 \mathrm{~mm}$ long $(9 \mathrm{~mm}$ inside root canal and $10 \mathrm{~mm}$ outside root canal) tapered and serrated glass fibre posts were used for Group B specimens. These posts correspond to the peso reamer size 2, which was also used for making canal space for cast metal post. Therefore, uniformity was achieved in preparing canal space.

30 specimens of Group A (Figure 2) were further divided into three subgroups (A1, A2 and A3) of 10 specimens each.

- Group A1: Control group with cast metal posts without any surface treatment.

- Group A2: Cast metal posts treated with 57\% ethyl alcohol for 3 minutes.

- Group A3: Cast metal posts air abraded with 50um alumina particles for 5 seconds from a distance of $30 \mathrm{~mm}$. 
30 specimens of Group B (Figure 3) were further divided into three subgroups (B1, B2 and B3) of 10 specimens each.

- Group B1: Control group with glass fibre posts without any surface treatment.

- Group B2: Glass fibre posts treated with 57\% ethyl alcohol for 3 minutes.

- Group B3: Glass fibre posts air abraded with 50um alumina particles for 5 seconds from a distance of $30 \mathrm{~mm}$.

All posts were marked at $9 \mathrm{~mm}$ from the apex using a permanent marker. These posts where luted in prepared canals with glass ionomer cement using lentulo spirals.

For measuring the retentive force, Universal testing machine (Figure 4) was used to apply tensile load to the post at a cross head speed of $2 \mathrm{~mm} / \mathrm{min}$. The force required to dislodge each post was recorded and the data was subjected to statistical analysis.



Figure 1: Custom made metal mold

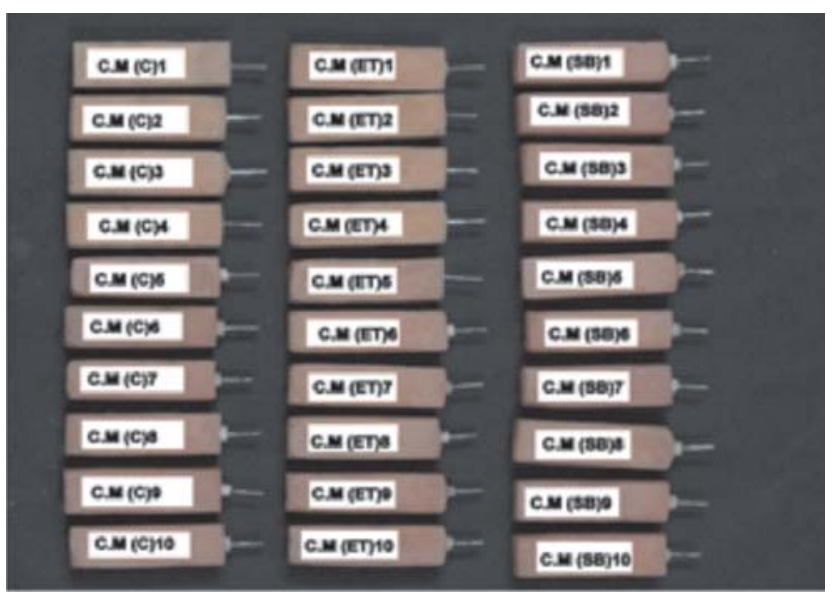

Figure 2: Specimens with cast metal posts



Figure 3: Specimens with glass fibre posts

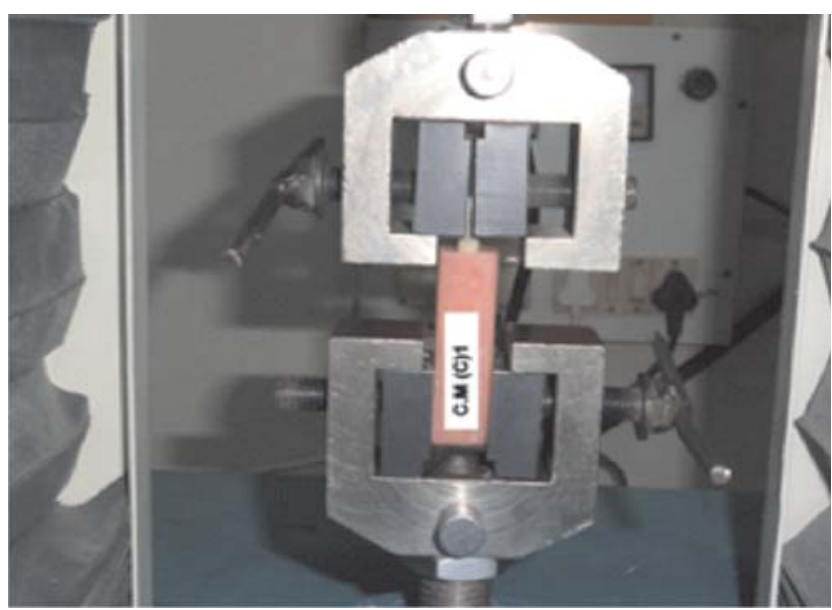

Figure 4: Universal testing machine for testing retentive strength

\section{RESULTS}

The effect of different surface treatments on the retention of custom made cast metal posts and prefabricated glass fibre posts was compared and evaluated. The measurements of retentive strength of two post types were subjected to statistical analysis to draw conclusion from the experimental data.

Two way ANOVA has been used to compute the statistical difference, variability and level of significance between the two main groups (cast metal and glass fibre posts) and three subgroups (control, ethanol treated and sand blasted). In the present study, it was seen that, there is a significant difference between the two main groups and between the three sub groups seen as a whole. Their P-value was also calculated, which also indicates the level of significance. For measuring the significance of the data individually and compare it within the same group and the other group, Critical Difference Values (C.D values) or least significant difference values was used. 
Table 1: Mean retentive strength of cast metal posts

\begin{tabular}{|l|l|l|l|l|}
\hline GROUP & SPECIMENS & MEAN & S.D & C.V \\
\hline A1 & 10 & 28.54 & 3.67183 & 12.9 \\
\hline A2 & 10 & 34.19 & 4.84426 & 14.2 \\
\hline A3 & 10 & 43.10 & 3.62495 & 8.4 \\
\hline
\end{tabular}

Table 2: Mean retentive strength of glass fibre posts

\begin{tabular}{|l|l|l|l|l|}
\hline GROUP & SPECIMENS & MEAN & S.D & C.V \\
\hline B1 & 10 & 22.27 & 3.81812 & 17.1 \\
\hline B2 & 10 & 24.72 & 3.13617 & 12.7 \\
\hline B3 & 10 & 28.12 & 2.42435 & 8.6 \\
\hline
\end{tabular}

Table 3: Determination of level of significance between the various subgroups *(Significant), **(Highly significant), NS(Non-significant)

\begin{tabular}{|l|l|l|l|l|l|l|}
\hline INTERACTIONS & A1 & A2 & A3 & B1 & B2 & B3 \\
\hline A1 & - & $5.650\left(^{* *}\right)$ & $14.560\left(^{* *}\right)$ & $6.270\left(^{* *}\right)$ & $3.820\left(^{*}\right)$ & $0.420(\mathrm{NS})$ \\
\hline A2 & - & - & $8.910(* *)$ & $11.920\left(^{* *}\right)$ & $9.470\left(^{* *}\right)$ & $6.070\left(^{* *}\right)$ \\
\hline A3 & - & - & - & $20.830\left(^{* *}\right)$ & $18.380(* *)$ & $14.980\left(^{* *}\right)$ \\
\hline B1 & - & - & - & - & $2.450(\mathrm{NS})$ & $5.850(* *)$ \\
\hline B2 & - & - & - & - & - & $3.400(\mathrm{NS})$ \\
\hline
\end{tabular}

Result of table 3 showed that ethyl alcohol surface treatment of cast metal posts significantly improved its retention. Sand blasting of cast metal posts showed more significant improvement in retention compared to both control group and ethyl alcohol treated group. In case of glass fibre posts, sand blasting significantly improved its retention compared to control group but no significant difference was observed between control and ethyl alcohol treated groups. There was also no significant difference between ethyl alcohol treated and sand blasted group.

\section{DISCUSSION}

Restoring endodontically treated teeth is a challenge when insufficient coronal tooth structure remains to support a restoration. Posts are widely used for restoring such teeth with insufficient coronal tooth structure to retain a core for the definitive prosthesis. Many in vitro studies have investigated various factors that affect retention of the post. These factors include length, design, diameter and the surface treatment of the post.

The purpose of this study was to evaluate and compare the effect of surface treatment with ethyl alcohol and air borne alumina particle abrasion on the retention of glass fibre post and cast metal post. The mean retentive values of three subgroups in both main groups (cast metal and glass fibre posts) indicated that sand blasted posts were most retentive followed by ethyl alcohol treated and control group posts. It came out to be $28.54 \mathrm{KgF}$ for control, 34.19 for ethanol treated and 43.10 for sand blasted in cast metal group (Table 1) and $22.27 \mathrm{KgF}$ for control, $24.72 \mathrm{KgF}$ for ethanol treated, and $28.12 \mathrm{KgF}$ for sandblasted in glass fibre posts group
(Table 2). The result of the study was in accordance with the study conducted by Nergiz et al (1997) ${ }^{7}$ while determining the retentive strength of tapered titanium posts with different surface texture. Their results showed that sand blasting of smooth tapered post more than doubled its retentive strength.

Study done by Kelsey, Latta, Kelsey $(2008)^{6}$ evaluated the effect of 2 surface roughening treatments (air abrasion with 50um alumina and Co-Jet surface roughening) on the retention of 3 types of dowels cemented with resin cement. They also arrived at the similar conclusion that surface roughening with air abrasion increased retention in dowels cemented with rein cement.

In the present study, it was seen that there was significant difference in retention achieved between the control and ethanol treated sub groups in cast metal post but the same difference was not significant in case of glass fibre posts. The difference in retention between ethanol treated and sand blasted specimens was again significant in case of cast metal posts but insignificant in glass fibre posts group. Difference between control and sandblasted sub groups was significant in both cast metal and glass fibre posts.

The findings observed may be because the non-abraded posts had a relatively smooth surface area, which limited mechanical interlocking between the post's surface and the glass ionomer cement. The airborne alumina particle-abraded posts were rougher and appeared to provide an increased surface area, which improved mechanical interlocking for the resin. Ethyl alcohol acts as solvent and dissolves surface impurities, making surface clean. It also acts as a disinfectant in the 
concentration of $20 \%$ to $70 \% .57 \%$ ethanol used in the present study is close to proof spirit, which is ethyl alcohol at $57.1 \%$. It was applied to the posts surfaces for 3 minutes and later air dried, which resulted in clean and smooth surface of posts. It does not create the irregularities as made by sand blasting of the post, hence there occurred difference in the retentive values of the two sub groups.

In present study, all posts were cemented with glass ionomer cement using lentulo spirals. It ensured the complete and dense fill of glass ionomer cement and standardized the method of application of cement to the post spaces. Diaz-Arnold, Vargas and Haselton (1999) reviewed the composition of 5 luting cements and reported that glass ionomer cement bonds to the tooth structure and had cariostatic effect and good long term results. Radke, Barkhodar and Podesta (1988) concluded that G.I.C had comparable retentive values as zinc phosphate whereas polycarboxylate and composite were less retentive.

Finally, the result of present study showed that sand blasting of posts is the best method to improve retention of posts. Ethyl alcohol pretreatment does not improve retention of glass fibre posts but has significant effect on the retention of cast metal posts. Overall retention of cast metal post group was more than the glass fibre post group.

However, only two factors were assessed to see their effect on retention of cast metal and glass fibre posts, further more extensive investigations with different factors should be undertaken for the purpose of improvement in the retention of posts.

\section{SUMMARYAND CONCLUSION}

From the present study, it was seen that:

1. In both cast metal and glass fibre post groups, sand blasting of posts was the better method to improve retention when compared with the ethanol treatment.
2. The mean retentive value of sand blasted group of cast metal group post was significantly better than both control and ethanol treated groups, whereas the mean retentive value of sand blasted glass fibre post group did not significantly improved compared to ethanol treated group, although it was significantly better than the control group.

3. Overall retention of cast metal post group was more than the glass fibre post group with any type of surface treatment method used in the study.

4. It was concluded that within the limitations of this study, sand blasting is an effective method to improve retention of both cast metal and glass fibre posts.

\section{REFERENCES}

1. Giovani AR, Vansan LP, Neto MDS, Paulino SM. In vitro fracture resistance of glass fiber and cast metal posts with different lengths. J Prosthet Dent 2009; 101 (3):183-188.

2. Insua AM, Silva LD, Rilo B, Santana U. Comparison of the fracture resistance of pulpless teeth restored with a cast post and core or carbon fiber post with a composite core. J Prosthet Dent 1998; 80 (5) :527-532.

3. Glamoc AG, Redzepagic S, Ajanovic M, Kazazic L, Zukic S, Dizdarevic D. Comparing the retention of cast posts cemented with three different kinds of cements. Pesq Bras Odontoped Clin Integr 2010; 10 (1):41-45.

4. Morgano SM, Milot P. Clinical success of cast metal posts and cores. J Prosthet Dent 1993; 70 (1):11-16.

5. Choi Y, Pae A, Park EJ, Wright RF. The effect of surface treatment of fiber reinforced posts on adhesion of a resinbased luting agent. J Prosthet Dent 2010; 103 (6) :362-368.

6. Kelsey WP, Latta MA, Kelesy MR. A comparison of the retention of three endodontic dowel system following different surface treatments. J Prosthodont 2008; 17 :269-273.

7. Nergiz I, Schmage P, Platzer U, Vogel CGM. Effect of different surface textures on retentive strength of tapered posts. J Prosthet Dent 1970; 78 (5) :451-457.

8. Diaz-Arnold AM, Vargas MA, Haselton DR. Current status of luting agents for fixed prosthodontics. J Prosthet Dent 1999; $81(2): 135-141$.

9. Radke RA, Barkhordar RA, Podesta RE. Retention of cast endodontic posts: comparison of cementing agents. J Prosthet Dent 1988;59(3):318-320. 